Fikroh : Jurnal Pemikiran dan Pendidikan Islam

Volume. 14, Number. 1, Januari 2021

p-ISSN : 2087-7501, e-ISSN : 2715-4459

HIm : 1-12

Journal Home Page : https://jurnal.stai-alazharmenganti.ac.id/index.php/fikroh

\title{
LATAR BELAKANG PENDIDIKAN ORANG TUA DAN POLA ASUH KELUARGA BERPENGARUH TERHADAP PERKEMBANGAN MORAL SPIRITUAL ANAK
}

\author{
Miftahudin \\ Universitas Bina Bangsa, Serang, Indonesia \\ miftahudin@binabangsa.ac.id
}

\begin{abstract}
Parents' educational background and family parenting affected on the development of children spiritual moral. The level of education possessed by parents was one of the factors that influenced parenting provided by parents to children which in turn will affect the development of child's spiritual moral, but that we need to know is the extent to which the role of these factors could influenced their spiritual moral development. Based on the research statement, the aimed of this research was to know the significant of parents' educational background and family parenting on the development of children spiritual moral in Islamic Junior High School of Al-khairiyah Pabuaran-Cilegon. This research used a survey method with a quantitative approach. From the result of the research known that parents' educational background effected on the development of children spiritual moral shown that $t_{\text {count }}>t_{\text {table }}$ $(5.030>2.0280)$, and family parenting affected on the development of children spiritual moral it's shown that tcount $>t_{\text {table }}(14.743>2.0280)$, and between $X_{1}$ and $X_{2}$ variable appeared that $r$ count was 0,51 all of which were greater than $r$ table 0,329, so it concluded that there was a significance influence of parents' educational background and family parenting on the development of children spiritual moral.
\end{abstract}

Keywords: Parents' Educational Background, Parenting, Spiritual Moral

\section{Abstrak}

Tingkat pendidikan yang dimiliki oleh orang tua menjadi salah satu faktor yang memengaruhi pola asuh yang diberikan orang tua pada anak yang pada akhirnya akan memengarhui perkembangan moral spiritual anak, namun yang perlu kita ketahui adalah sejauh mana peran faktor tersebut dapat memengaruhi perkembangan moral spiritual mereka, apakah benar adanya bahwa anak dari seseorang yang berlatar belakang Pendidikan yang tinggi akan mendapatkan bimbingan atau pola asuh yang baik sehingga berdampak positif bagi perkembangan anak atau sebaliknya, anak yang berasal dari orang orang tua yang memiliki pendidikan rendah akan terhambat perkembangannya. 


\section{Miftahudin}

Berdasarkan pernyataan penelitian yang telah dikemukakan, maka tujuan penilitian ini adalah untuk mengetahui signifikansi latar belakang Pendidikan orang tua dan pola asuh keluarga terhadap perkembangan moral spiritual anak di MTs Al-Khairiyah Pabuaran - Cilegon. Adapun metode penelitian yang digunakan adalah metode survey dengan pendekatan kuantitatif. Dari hasil penelitian yang telah dilaksanakan diketahui bahwa latar belakang Pendidikan orang tua berpengaruh terhadap perkambangan moral spiritual anak ditunjukkan dengan nilai $t_{\text {hitung }}>t_{\text {tabel }}(5.030>2.0280)$, dan pola asuh keluarga berpengaruh terhadap perkembangan moral spiritual anak yang ditunjukkan dengan nilai $t_{\text {hitung }}>t_{\text {tabel }}(14.743>2.0280)$ serta antara variable $\mathrm{X}_{1}$ dan $\mathrm{X}_{2}$ tampak bawha $\mathrm{r}$ hitung yaitu 0,51 yang kesemuanya itu lebih besar dari $\mathrm{r}$ tabel 0,329 sehingga dapat disimpulkan bahwa terdapat pengaruh yang signifikan dari latar belakang pendidikan orang tua dan pola asuh keluarga terhadap perkembangan moral spiritual anak.

Kata kunci: Latar Belakang Pendidikan Orang Tua, Pola Asuh, Moral Spiritual

\section{A. Pendahuluan}

Ciri khas manusia yang membedakannya dari hewan terbentuk dari kumpulan yang terpadu (integrated) dari apa yang disebut sifat hakikat manusia, kata hati dan moral adalah salah satu wujud dari sifat hakikat manusia, jika kata hati diartikan sebagai bentuk pengertian yang menyertai perbuatan, maka yang dimaksud dengan moral atau etika adalah perbuatan itu sendiri. ${ }^{1}$ Salah satu dimensi dari hakikat manusia adalah dimensi keberagamaan yang mana Pendidikan agama seyogyanya menjadi tugas orang tua dalam lingkungan keluarga. Disamping itu pula penanaman sikap dan kebiasaan dalam beragama dimulai sedini mungkin meskipun masih terbatas pada latihan (babit formation), ${ }^{2}$ tetapi untuk pengembangannya tidak dapat diserahkan hanya kepada orang tua, untuk itu dapat pula dibantu oleh Pendidikan di sekolah.

Pendidikan adalah merupakan salah satu kebutuhan hidup yang sangat penting, karena dengan pendidikan seseorang bisa mendapatkan ilmu pengetahuan tentang sesuatu, dengan pendidikan seseorang mampu menggapai impiannya, bahkan dengan pengetahuan pula seseorang mampu melahirkan terobosan baru. Dalam hal ini pendidikan seseorang bisa memengaruhi jalan pikirannya dalam segala aspek. Baik dalam hal

${ }^{1}$ Umar Tirtarahardja dan S.L La Sulo, Pengantar Pendidikan (Jakarta: Rineka Cipta, 2005), 58.

2 Umar Tirtahardja, Pengantar Pendidikan, 23. 
penampilan, gaya bahasa, bersosialisasi dengan lingkungan, baik lingkungan sosial yang bersifat intern, maupun lingkungan sosial yang bersifat ekstern.

Namun ironisnya, masih banyak orang yang belum mengetahui atau tak mau tahu akan pentingnya pendidikan yang menyebabkan mereka jadi tak berilmu sehingga hal tersebut diwariskan kepada garis keturunannya, ini diakibatkan oleh rendahnya tingkat pendidikan yang telah ditempuh oleh mereka sehingga dapat memengaruhi kesadarannya untuk mendidik anak-anak agar dapat mengenyam pendidikan yang lebih tinggi, juga dengan tingkat pendidikan yang rendah menyebabkan kurang terbimbingnya anak-anak mereka yang masih bersekolah dan pada akhirnya dapat memengaruhi perkembangan anak-anak mereka. Perkembangan yang terjadi pada anak tidak hanya terbatas pada pengertian perubahan secara fisik, melainkan di dalamnya juga mencakup serangkaian perubahan yang secara terus menerus dari fungsi-fungsi jasmaniah maupun rohaniah yang dimiliki individu menuju tahap kematangan, melalui pertumbuhan dan belajar. ${ }^{3}$

Setiap fenomena atau gejala perkembangan anak merupakan produk dari kerjasama dan pengaruh timbal balik antara potensi hereditas dengan faktor lingkungan. ${ }^{4} \mathrm{Hal}$ ini mengharuskan pendidik atau orang tua untuk melakukan usaha-usaha dalam menciptakan lingkungan belajar yang kondusif, memotivasi kegiatan anak untuk belajar, dan membimbing perkembangan anak kearah perkembangan optimal. ${ }^{5}$

Tingkat pendidikan yang dimiliki orang tua menjadi salah satu faktor yang memengaruhi perkembangan anak karena dengan faktor itu seorang anak akan memperoleh atau tidak memperoleh bimbingan yang diberikan oleh orang tua mereka. Namun yang perlu kita ketahui, sejauh mana peran faktor tersebut dapat mempengaruhi perkembangan mereka, apakah benar adanya sebuah anggapan bahwa anak dari seorang yang berlatar belakang pendidikan yang tinggi akan mendapatkan bimbingan yang baik sehingga dapat berdampak positif begi perkembangan mereka atau sebaliknya, anak yang berasal dari orang tua yang memeiliki penididikan yang rendah akan terhambat perkembangannya. Oleh karenanya, masalah ini merupakan hal yang harus diketahui oleh

${ }^{3}$ Desmita, Psikologi Perkembangan (Bandung: PT. Remaja Rosda Karya, 2005), 4.

${ }^{4}$ Kartono Kartini, Psikologi Anak (Bandung: Mandar Maju, 2005), 21.

${ }^{5}$ Wasty Soemanto, Psikologi Pendidikan: Landasan Kerja Pemimpin Pendidikan (Jakarta: PT. Rineka Cipta, 2000), 58. 


\section{Miftahudin}

seluruh orang tua demi perkembangan anak-anaknya, karena orang tua dan keluarga merupakan pendidikan awal bagi seorang anak baik dalam segi perkembangan maupun pertumbuhannya.

Sedangkan Pola asuh orang tua merupakan sikap dan cara orang tua dalam mempersiapkan anggota keluarga yang lebih muda termasuk anak supaya dapat mengambil keputusan sendiri dan bertindak sendiri sehingga mengalami perubahan dari keadaan bergantung kepada orang tua menjadi berdiri sendiri dan bertanggung jawab sendiri. ${ }^{6}$

Salah satu perkembangan yang terjadi pada diri anak adalah perkembangan moral spiritual. Secara etimologi moral berarti ajaran baik buruk yang diterima baik mengenai perbuatan, sikap, kewajiban, akhlak, budi pekerti, susila dan sebagainya. Sedangkan keagamaan diartikan sebagai tata cara hidup yang berhubungan dengan Tuhan. ${ }^{7}$ Dalam hal perkembangan moral pada diri anak berdasarkan hasil penelitian empiris yang dilakukan Kohlberg (1958) dalam jurnal Asti Inawati menyatakan bahwa tahapan perkembangan moral seseorang akan melewati tiga tahapan anatara lain: ${ }^{8}(1)$. Tingkat pra konvensional: pada tingkat ini anak tanggap terhadap aturan-aturan budaya dan terhadap ungkapanungkapan budaya mengenai baik dan buruk, benar dan salah. Akan tetapi hal ini sematamata di tafsirkan dari sgi sebab akibat fisik atau kenikmatan perbuatan (hukum, keuntungan, pertukaran dan kebaikan. (2). Tingkat konvesional: pada tingkat ini anak hanya menuruti harapan keluarga atau kelompok, ia memandang bahwa hal tersebut bernilai bagi dirinya sendiri, tanpa mengindahkan akibat yang segera dan nayata sikapnya tidak hanya konformatis terhadap harapan pribadi dan sosial, melainkan juga setia terhadapnya dan secara aktif mempertahankan, mendukung dan membenarkannya. (3). Tingkat pasca konvensional: pada tingkat ini perkermbangan moral manusia banyak dilandasi oleh pola pikirnya sendiri, pada tingkatan ini pula seorang anak telah memiliki kemampuan sendiri dalam menentukan segala keputusan sikap dan perilaku moralitasnya.

\section{B. Metode Penelitian}

\footnotetext{
6Singgih D. Gunarsa dan Gunarsa, Singgih D, Psikologi Remaja (Jakarta: Gunung Mulia, 2007), cet. 16, 109. ${ }^{7}$ W.J.S Poerwadarminta, Kamus Umum Bahasa Indonesia (Balai Pustaka, Jakarta, 1976), 19.

${ }^{8}$ Asti Inawati, "Strategi Pengembangan Moral dan Nilai Agama Anak Usia Dini," Al-Athfal: Jurnal Pendidikan Anak, 3, no. 1 (2017): 54.
} 
Penelitian ini dilakukan dengan menggunakan metode survey dengan pendekatan kuantitatif, metode ini disebut juga sebagai metode positivistik karena berlandaskan pada filsafat positivisme, penelitian kuantitatif pada dasarnya menggunakan pendekatan yang berangkat dari suatu kerangka teori, gagasan para ahli, maupun pemahaman peneliti/penulis bedasarkan pengalamannya, kemudian dikembangkan menjadi sebuah permasalahan beserta pemecahannya yang diajukan untuk memperoleh sebuah pembenaran dalam bentuk dukungan empiris dilapangan. Dalam penelitian ini yang di analisis adalah latar belakang Pendidikan orang tua dan pola asuh keluarga terhadap perkembangan moral spiritual anak.

Populasi dalam penelitian ini yaitu seluruh siswa pada MTs Al-khairiyah Pabuaran Cilegon yang berjumlah 190 siswa, tetapi data yang dianalisis adalah data sampel yang diambil dari populasi tersebut yang berjumlah 38 siswa. Teknik pengumpulan data yang digunakan dalam penelitian ini yaitu observasi, kuesioner, dan dokumentasi, dan dari hasil pengumpulan data kemudian diolah dengan menggunakan serangkaian uji asumsi klasik dan uji hipotesis yaitu uji t dan uji anova untuk menjawab dugaan dalam penelitian ini, uji $\mathrm{t}$ digunakan untuk menguji signifikansi dari pengaruh variabel independen secara individual terhadap variabel dependen, sedangkan uji Anova untuk mengetahui variabel independen apakah secara bersama-sama berpengaruh terhadap variabel dependen.

\section{Hasil dan Pembahasan}

Hasil dari penelitian ini berdasarkan hasil persamaan regresi, nilai konstanta variabel perkembangan moral spiritual anak adalah sebesar -5.964 , hal ini berarti jika tidak ada variabel latar belakang pendidikan orang tua atau $\mathrm{X}_{1}=0$ dan pola asuh keluarga atau $\mathrm{X}_{2}=$ 0 maka perkembangan moral spiritual anak akan tetap -5.964 satuan. Selanjutnya hasil analisis linear berganda dapat dilihat pada table sebagaimana berikut:

Tabel 1. Hasil Uji Regresi Linear Berganda

Coefficients $^{a}$

\begin{tabular}{|c|c|c|c|c|c|}
\hline \multirow[b]{2}{*}{ Model } & \multicolumn{2}{|c|}{$\begin{array}{c}\text { Unstandardized } \\
\text { Coefficients }\end{array}$} & \multirow{2}{*}{$\begin{array}{c}\begin{array}{c}\text { Standardized } \\
\text { Coefficients }\end{array} \\
\text { Beta }\end{array}$} & \multirow[b]{2}{*}{$\mathrm{t}$} & \multirow[b]{2}{*}{ Sig. } \\
\hline & $\mathrm{B}$ & Std. Error & & & \\
\hline
\end{tabular}




\begin{tabular}{|l|c|c|c|c|c|}
\hline (Constant) & -5.964 & 3.700 & & - & .116 \\
Latar Belakang & .389 & .107 & .230 & 3.647 & .001 \\
Pendidikan Orang Tua & & & & & \\
(X1) & .875 & .068 & .809 & 12.83 & .000 \\
Pola Asuh Keluarga & & & & 1 & \\
(X2)
\end{tabular}

a. Dependent Variable: Perkembangan Moral Spiritual (Y)

Sumber: Perbitungan SPSS for Windows Version 23

Untuk mengetahui lebih jelas seberapa besar masing-masing variabel independen memengaruhi varibel dependen dapat dilihat pada uraian sebagai berikut:

\section{Latar Belakang Pendidikan Orang Tua Berpengaruh terhadap Perkembangan Moral Spiritual Anak}

Berdasarkan hasil uji t pada tabel di bawah ini dapat dilihat bahwa variabel latar belakang pendidikan orang tua berpengaruh terhadap perkembangan moral spiritual anak, hal ini ditunjukkan dengan $t_{\text {hitung }}>t_{\text {tabel }}(5.030>2.0280)$, dengan nilai signifikan $0.000<0.05$. Berdasarkan uji signifikansi diperoleh bahwa terdapat pengaruh latar belakang pendidikan orang tua terhadap perkembangan moral spiritual anak.

Tabel 2. Uji Hipotesis Parsial (Uji t) Variabel $\mathbf{X}_{1}$ terhadap Variabel $Y$

Coefficients $^{\mathrm{a}}$

\begin{tabular}{|c|c|c|c|c|c|}
\hline \multirow[b]{2}{*}{ Model } & \multicolumn{2}{|c|}{$\begin{array}{l}\text { Unstandardized } \\
\text { Coefficients }\end{array}$} & \multirow{2}{*}{$\begin{array}{c}\text { Standard } \\
\text { ized } \\
\text { Coefficie } \\
\text { nts } \\
\text { Beta }\end{array}$} & \multirow[b]{2}{*}{$\mathrm{t}$} & \multirow[b]{2}{*}{ Sig. } \\
\hline & B & Std. Error & & & \\
\hline $\begin{array}{l}\text { (Constant) } \\
\text { Latar Belakang }\end{array}$ & 9.942 & 8.209 & & 1.211 & .234 \\
\hline $\begin{array}{c}\text { Pendidikan Orang Tua } \\
\text { (X1) }\end{array}$ & 1.087 & .216 & .642 & 5.030 & .000 \\
\hline
\end{tabular}


a. Dependent Variable: Perkembangan Moral Spiritual (Y)

Sumber: Perbitungan SPSS for Windows Version 23

Dengan adanya hubungan positif antara latar belakang pendidikan orang tua dengan perkembangan moral spiritual anak, hal ini memberikan gambaran bagi orang tua kepada anak, agar orang tua lebih bisa memberikan dorongan dan pemahaman tentang pentingnya pendidikan yang nantinya akan berguna di hari kelak ketika anakanak telah beranjak dewasa yang suatu saat akan menjadi orang tua. Hasil penelitian ini sejalan dengan beberapa hasil penelitian terdahulu yang telah dilakukan oleh Sri Reskia, Herlina dan Zulnuraini yang menyatakan bahwa tingkat Pendidikan orang tua memiliki pengaruh signifikan dan kuat terhadap prestasi belajar dan perkembangan moral anak, yang mana peran orang tua sangat penting dalam perkembangan moral anak. Begitu pula penelitian yang dilakukan oleh Muhsinin juga mengatakan yang sama bahwa dengan semakin tinggi nilai pendidikan keagamaan orang tua kecenderungan perkembangan nilai-nilai moral dan agama anak juga akan baik.

\section{Pola Asuh Keluarga Berpengaruh terhadap Perkembangan Moral Spiritual Anak}

Dari hasil uji t antar variabel pola asuh keluarga terhadap perkembangan moral spiritual anak menunjukkan bahwa $\mathrm{t}_{\text {hitung }}>\mathrm{t}_{\text {tabel }}(14.743>2.0280)$, dengan nilai signifikan $0.000<0.05$. Berdasarkan hasil di atas disimpulkan bahwa terdapat pengaruh pola asuh keluarga terhadap perkembangan moral spiritual anak.

Tabel 3. Uji Hipotesis Parsial (Uji t) Variabel $X_{2}$ terhadap Variabel $Y$

Coefficients $^{a}$

\begin{tabular}{|c|c|c|c|c|c|}
\hline \multirow[b]{2}{*}{ Model } & \multicolumn{2}{|c|}{$\begin{array}{c}\text { Unstandardized } \\
\text { Coefficients }\end{array}$} & $\begin{array}{l}\text { Standardize } \\
\mathrm{d} \\
\text { Coefficients }\end{array}$ & & \\
\hline & $\mathrm{B}$ & Std. Error & Beta & $\mathrm{t}$ & Sig. \\
\hline $\begin{array}{ll}1 & \text { (Constant) } \\
& \text { Pola Asuh Keluarga } \\
\text { (X2) }\end{array}$ & $\begin{array}{l}2.607 \\
1.002\end{array}$ & 3.310 & .926 & $\begin{array}{c}.788 \\
14.74 \\
3\end{array}$ & $\begin{array}{l}.436 \\
.000\end{array}$ \\
\hline
\end{tabular}

a. Dependent Variable: Perkembangan Moral Spiritual (Y) 


\section{Miftahudin}

Sumber: Perbitungan SPSS for Windows Version 23

Hasil ini pula menunjukkan bahwa bila pola asuh keluarga yang diterapkan dalam rumah tangga cocok dan sesuai dengan karakter anak maka dapat dipastikan bahwa anak akan mengalami perkembangan yang maksimal dan signifikan karena tidak dipungkiri bahwa anak lebih banyak berada di rumah dibandingkan di sekolah dan guru pertama mereka adalah orang tua. Hasil penelitian ini sependapat dengan hasil penelitian Risna Ayuana Fil Is dan Renita Yulia Astari yang mengemukakan bahwa pola asuh orang tua memiliki pengaruh yang signifikan terhadap perkembangan moral anak, dalam hal penerapan pola asuh terhadap anak ada beberapa bentuk pola asuh yang dapat orang tua terapkan kepada anak dalam membentuk moral spiritual anak, diantaranya adalah:

\section{Pola asuh demokratis}

pola asuh ini ditandai dengan adanya pengakuan orang tua terhadap kemampuan anak, anak diberi kesempatan untuk tidak selalu tergantung kepada orang tua, orang tua sedikit memberi kebebasan untuk memilih yang terbaik baginya, pendapatnya didengarkan, dilibatkan dalam pembicaraan terutama yang menyangkut dengan kehidupan anak itu sendiri, anak diberi kesempatan untuk mengembangkan kontrol internalnya sehingga sedikit demi sedikit berlatih untk bertanggung jawab kepada diri sendiri dan diberi kesempatan untuk berpartisipasi dalam mengatur hidupnya. ${ }^{9}$ Orang tua yang mendidik anaknya dengan sikap/pola demokratis akan selalu menjada komunikasi orang tua dan anak, dalam membangun komunikasi ini orang tua harus memperhatikan perinsip-prinsip yaitu: (1) menyediakan waktu, (2) berkomunikasi secara pribadi, (3) menghargai anak, (4) mengerti anak, (5) mempertahankan hubungan dan (6) menerima kritik.

\section{Pola asuh otoriter}

pola asuh ini merupakan cara mendidik anak dengan menggunakan kepemimpinan otoriter, kepemimpinan otoriter yaitu pemimpin menentukan semua kebijakan, langkah dan tugas yang harus dijalankan. Pola asuh semacam ini ditandai dengan cara mengasuh anak dengan aturan yang ketat, sering kali memaksa anak untuk berperilaku seperti dirinya (orang tua), kebebasan untuk bertindak atas nama diri sendiri

${ }^{9}$ Chabib Thoha, Kapita Selekta Pendidikan Islam, (Yogyakarta: Pustaka Pelajar Offset, 2003), 111 
dibatasi, anak jarang diajak berkomunikasi, bercerita, bertukar pikiran dengan orang tua. Orang tua malah menganggap bahwa semua sikap yang dilakukan itu sudah benar sehingga tidak perlu minta pertimbangan anak atas semua keputusan yang mengangkat permasalahan anak-anaknya. Pola asuh yang bersifat otoriter ini juga ditandai dengan hukuman-hukuman yang dilakukan dengan keras, anak juga diatur dengan berbagai macam aturan yang membatasi perlakuannya.

\section{Pola asuh permisif}

pola asuh semacam ini adalah bentuk pola asuh dengan membiarkan anak bertindak sesuai dengan keinginannya, orang tua tidak memberikan hukuman dan pengendalian. ${ }^{10}$ Pola asuh ini ditandai dengan adanya kebebasan tanpa batas pada anak untuk berperilaku sesuai dengan keinginannya sendiri, orang tua tidak pernah memberikan aturan dan pengarahan kepada anak, sehingga anak akan berperilaku sesuai dengan keinginannya sendiri walaupun terkadang bertentangan dengan norma sosial. Dalam hal ini Elizabeth B Hurlock berpendapat disiplin permisif tidak membimbing ke pola perilaku yang disetujui secara sosial dan tidak menggunakan hukuman. ${ }^{11}$ Pola asuh model ini sebaiknya diterapkan oleh orang tua ketika anak telah dewasa, di mana anak sudah dapat memikirkan untuk dirinya sendiri, mampu bertanggung jawab atas perbuatan dan tindakannya.

\section{Latar Belakang Pendidikan Orang Tua dan Pola Asuh Keluarga Berpengaruh terhadap Perkembangan Moral Spiritual Anak}

Berdasarkan hasil uji anova didapatkan $\mathrm{F}_{\text {hitung }}>\mathrm{F}_{\text {tabel }}(152.467>3.27)$ yang artinya latar belakang pendidikan orang tua dan pola asuh keluarga memiliki pengaruh yang signifikan terhadap perkembangan moral spiritual anak di MTs Al-Khairiyah Pabuaran - Cilegon.

\section{Tabel 4. Hasil Uji F}

\section{ANOVA $^{\mathrm{a}}$}

\begin{tabular}{|l|l|l|l|l|l|}
\hline Model & $\begin{array}{l}\text { Sum of } \\
\text { Squares }\end{array}$ & $\mathrm{df}$ & $\begin{array}{c}\text { Mean } \\
\text { Square }\end{array}$ & $\mathrm{F}$ & Sig. \\
\hline
\end{tabular}

${ }^{10}$ Hadi Subroto M.S., Mengembangkan Kepribadian Anak Balita, (Jakarta: Gunung, 2007), 5

${ }^{11}$ Elizabeth B. Hurloch, Child Developmen, Terj oleh Meitasari Tjandrasa,Perkembangan Anak, Jilid II, 93 


\begin{tabular}{|cc|c|c|c|c|c|}
\hline 1 & Regression & 1564.436 & 2 & 782.218 & 152.467 & $.000^{\mathrm{b}}$ \\
& 179.564 & 35 & 5.130 & & \\
Residual & 1744.000 & 37 & & & \\
Total & & & & \\
\hline
\end{tabular}

a. Dependent Variable: Perkembangan Moral Spiritual $(\mathrm{Y})$

b. Predictors: (Constant), Pola Asuh Keluarga (X2), Latar Belakang Pendidikan Orang Tua (X1)

Sumber: Perbitungan SPSS for Windows Version 23

Dari hasil analisa di atas dapat diambil sebuah implikasi yang menunjukkan bahwa latar belakang pendidikan orang tua serta pola asuh keluarga yang diterapkan dalam keluarga sangat berperan dalam menunjang perkembangan anak, karena pendidikan anak yang pertama kali ditempuh adalah di dalam keluarga, bagaimana anak akan berkembang dengan pesat dan baik jika guru dalam keluarga tersebut tidak mengetahui bagaimana yang harus dilakukan dan bagaimana pola pendidikan yang akan diterapkan kepada anak-anak. Hasil penelitian di atas sejalan dengan hasil penelitian yang telah dilakukan oleh Irsalina Rahma yang menunjukkan bahwa terdapat hubungan yang kuat dan signifikan antara tingkat Pendidikan formal orang tua dengan pola pengasuhan dalam perkembangan moral anak di desa Menoreh Kecamatan Salaman Kabupaten Magelang, akan tetapi penelitian ini tidak sejalan dengan hasil penelitian yang telah dilakukan Rahayu Budi Utami yang menjelaskan bahwa tingkat Pendidikan orang tua tidak memengaruhi perkembangan psikososial anak, namun tipe pola asuh berpengaruh terhadap perkembangan psikososial anak, dimana penerapan pola asuh yang tidak sesuai dengan kondisi anak akan memengaruhi perkembangan psikososialnya.

\section{Simpulan}

Berdasarkan hasil penelitian dan pembahasan yang telah dilakukan, dapat disimpulkan sebagai berikut: (1) Terdapat pengaruh latar belakang pendidikan orang tua terhadap perkembangan moral spiritual anak, dibuktikan dengan $t_{\text {hitung }}>t_{\text {tabel }}(5.030>$ 2.0280). hal ini berarti semakin tinggi latar belakang pendidikan orang tua diharapkan dapat memberikan perkembangan moral spiritual anak lebih baik lagi. (2) Terhadap pengaruh pola asuh keluarga terhadap perkembangan moral spiritual anak, hal ini 
dibuktikan dengan nilai $t_{\text {hitung }}>t_{\text {tabel }}(14.743>2.0280)$, yang berarti semakin tinggi pola asuh keluarga maka akan menigkatkan perkembangan moral spiritual anak. (3) Terdapat pengaruh yg posisitf dan signifikan dari latar belakang pendidikan orang tua dan pola asuh keluarga terhadap perkembangan moral spiritual anak yang dibuktikan dengan $F_{\text {hitung }}>$ $\mathrm{F}_{\text {tabel }}(152.467>3.27)$, kombinasi latar belakang pendidikan orang tua dan pola asuh keluarga akan memberikan dampak yang signifikan terhadap perkembangan moral spiritual anak. Kontribusi dari kedua variabel independen tersebut secara bersama-sama (simultan) yaitu sebesar 0.897 atau $89.70 \%$ terhadap perkembangan moral spiritual anak.

\section{E. Daftar Pustaka}

Amin, Mansyur dan Muhammad Najib. Agama, Demokrasi dan Transformasi Sosial, Yogyakarta: LPKSMNV DIY bekerjasama dengan The Asia Fondation Jakarta, 2001.

Arifin, Imron. Penelitian kualitatif dalam ilmu-ilmu sosial dan keagamaan. Malang: Kalimasada Press, 2001.

Arikunto, Suharsimi. Evaluasi Program Pendidikan. Jakarta: Bina Aksara, 2009. 2003. . Prosedur Penelitian Suatu Pendekatan Praktek. Jakarta: Rineka Cipta,

B. Hurloch Elizabeth. Child Developmen, Terj oleh Meitasari Tjandrasa, Perkembangan Anak. Jilid II.

C. P. Chaplin. Dictionary of Psychology, terj. Jakarta: Raja Grafindo Persada, cet. ke-8, 2006.

Crow dan Crow. Pengantar Ilmu Pendidikan. Yogayakarta: Rake Sarasin, 2001.

David off, L. L. Introduction to Psychology, terj. Mari Juniati. Jakarta: Erlangga, 2000.

Desmita. Psikologi Perkembangan. Bandung: PT. Remaja Rosda Karya, 2005.

Drajat, Zakiyah. Pendidikan Islam dalam Keluarga dan Sekolah. Jakarta: Remaja Rosdakarya Offset, 2001.

Gunarsa, Ny. Y. Singgih D. dan Gunarsa, Singgih D. Psikologi Remaja. Jakarta: Gunung Mulia, cet. 16, 2007.

Hadjar, Ibnu. Dasar-dasar metodologi penelitian kuantitatif dalam pendidikan. Jakarta: PT. Raja Grafindo Persada, 1999.

Hamalik, Oemar. Psikologi Belajar Mengajar. Bandung: Sinar Baru Algesindo, 2009.

Hasan, Fuad. Dasar-dasar Kependidikan. Jakarta: Rineka Cipta, 2003.

Hasabullah. Dasar-Dasar Ilmu Pendidikan. Jakarta: Raja Grafindo Persada, 2001. 
Hurloch, Elizabeth B. Perkembangan Anak, Terj oleh Meitasari Tjandrasa Jilid II. Jakarta: Erlangga, 2002.

Kartono, Kartini. Psikologi Anak. Bandung: Mandar Maju, 2005.

Monks, Knoers F. J. A. M. P. Ontwikkelings Psychology, terj. Siti Rahayu Haditono. Yogyakarta: Gadjah Mada University Press, 2008.

Mardalis. Metode Penelitian Suatu Pendekatan Proposal. Jakarta: Bumi Aksara, 2003.

Nazir, Moh. Metode Penelitian. Bogor: Ghalia Indonesia, 2005.

Nugraha, Ali dan Neny Ratnawati. Kiat Merangsang Kecerdasan Anak: Panduan Agar Anak Komunikatif dan Berfikir Kreatif. Jakarta: Puspa Swara, 2004.

Seifert, K. L. dan Hoffnung R. J. Child and Adolescent Development. Boston: Houghton Mifflin Company, 2004.

Sinolungan, A. E. Psikologi Perkembangan Peserta Didik. Jakarta: Gunung Agung, 2002.

Soemanto, Wasty. Psikologi Pendidikan: Landasan Kerja Pemimpin Pendidikan. Jakarta: PT. Rineka Cipta, 2000.

Subroto, Hadi M. S. Mengembangkan Kepribadian Anak Balita. Jakarta: Gunung Agung, 2007.

Sukmadinata, Nana Syaodih. Landasan Psikologi Proses Pendidikan. Bandung: PT. Remaja Rosdakarya, 2003.

Syah, Muhibbin. Psikologi Belajar. Jakarta: Rajawali Press, 2009.

Tirtarahardja, Umar dan S. L. La Sulo. Pengantar Pendidikan (Edisi Revisi). Jakarta: Rineka Cipta, 2005.

Thohah, Chabib. Kapita Selekta Pendidikan Islam. Yogyakarta: Pustaka Pelajar Offset, 2003.

Whiterington, H. C. Psikologi Pendidikan (Terjm. M. Buchori). Jakarta: Aksara Baru, 2003.

Yusuf, Syamsu, LN. Psikologi Perkembangan Anak dan Remaja. Bandung: Remaja Rosdakarya, 2008.

Zainuddin dkk. Seluk Beluk Pendidikan dari Al-Ghazali. Jakarta: Bumi Aksara, 2001. 